\title{
Numerical Simulation and Optimization of Indirect Squeeze Casting Process
}

\author{
Liwen Chen, ${ }^{1}$ Jingyi Li, ${ }^{1}$ Yuhong Zhao, ${ }^{1,}{ }^{*}$ Muxi Li, ${ }^{1}$ Limin $\mathrm{Li},{ }^{1}$ Lei Chen ${ }^{2}$ and Hua Hou ${ }^{1}$
}

\begin{abstract}
In order to optimize the process of indirect squeeze casting, computer aided engineering (CAE) technology was used to predict casting defects. Taking an adapter ring casting as an example, its 3D-model was established and its casting process was designed. The results indicate that, for indirect squeeze casting, when the liquid metal injects to mold cavity by casting system, temperature of liquid metal has dropped and started to solidify. At the same time, the runner has begun to solidify. If the cross-section of runner is too small, the runner pressure has not passed the casting to produce the effect of feeding, therefore this problem will lead to casting defects such as shrinkage cavity. As a result, full consideration should be given to the feeding effect of the runner in mold design. Simulation software can be used to simulate the temperature field of casting filling and solidification to design the runner reasonably.
\end{abstract}

Keywords: Indirect squeeze casting; Computer numerical simulation; Process optimization.

Received: 6 November 2020; Accepted: 30 December 2020.

Article type: Research article.

\section{Introduction}

As an advanced near-net forming technology, squeeze casting (SC) is one of the preferred processes for producing highperformance aluminum alloy parts, which has the advantages of simple and easy casting process, low cost, reliable and highquality forging products. ${ }^{[1,2]}$

Squeeze casting technology is a technological method to obtain castings by applying high mechanical pressure on liquid metal poured into the mold cavity and making it form and solidify. ${ }^{[3]}$ The squeeze casting technology can be divided into direct squeeze casting and indirect squeeze casting. ${ }^{[4]}$ Indirect squeeze casting uses the forming punch to squeeze the liquid metal into the mold cavity and pass the pressure to the casting through the inner runner composed of a punch and a concave mold. Compared with the die casting process, this squeeze casting process can effectively improve the casting shrinkage and forming ability, avoid and reduce the casting defects such as porosity, and improve the mechanical properties of casting. ${ }^{[5,6]}$

In this paper, taking an aluminum alloy adapter ring casting

${ }^{I}$ College of Materials Science and Engineering, North University of

China, Taiyuan, 030051, China.

${ }^{2}$ Fenxi Shanxi Heavy Industry Co., Ltd., Taiyuan, 030027, China.

*E-Mail: zhaoyuhong@nuc.edu.cn (Y. Zhao) as an example, ProCAST casting simulation software was used to simulate and improve the process.

\section{Numerical simulation of adapter ring casting}

2.1 Determination of casting process scheme

According to the structural characteristics and casting technical requirements of the adapter ring, a 3D model of the part forming scheme was established, as shown in Fig. 1. The casting system mainly consists of a spure, a runner and an ingate. Under the pressure of the punch on the squeeze casting machine, the metal liquid passes through the spure, the runner, the ingate and enters the mold cavity for filling. ${ }^{[7,8]}$ The upper form of the mold is provided with vents, which can discharge the air from the mold cavity during the process of slowly filling the mold with liquid metal.
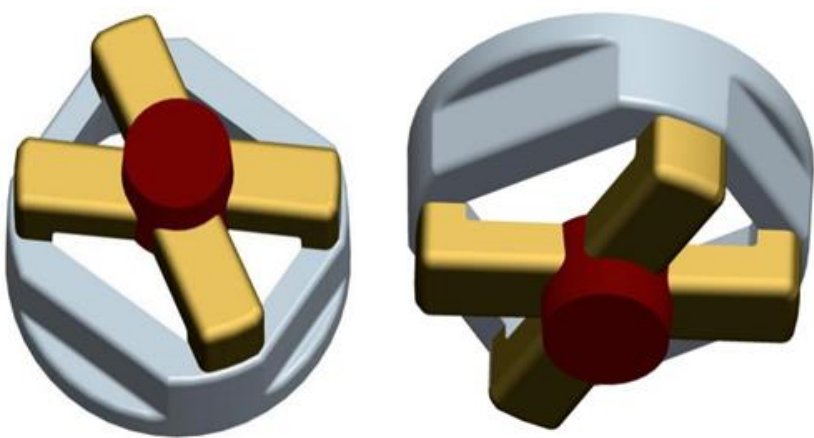

Fig. 1 Indirect squeeze casting forming scheme for adapter ring castings. 


\subsection{Pre-processing of Numerical simulation}

At first, the casting, runner and die were mesh-divided by finite element method. The Visual-Mesh module was used to check and assemble the geometric structure of the model, divide the surface and volume Mesh. Finally, grid division was completed. ${ }^{[9]}$ The total number of grids is 502237, in which the number of surface grids is 32720 and the number of volume grids is 469517 . Fig. 2 shows the casting and casting system with a good mesh division.

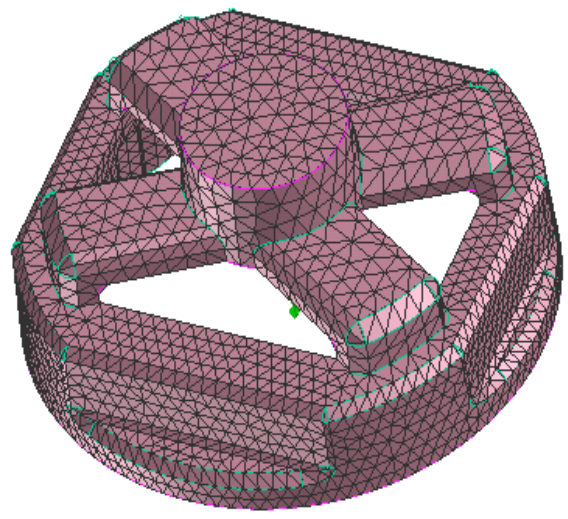

Fig. 2 Casting and casting system with mesh division.

Then the initial conditions and filling parameters are set to determine the specific process parameters of numerical simulation, ${ }^{[10]}$ the specific process parameters are shown in Table 1, which shows that the casting material was set as aluminum alloy $\mathrm{ZL} 101$ with the initial temperature of $700^{\circ} \mathrm{C}$, and the mold material was set as steel $\mathrm{H} 13$ with the initial temperature of $150^{\circ} \mathrm{C}$. The mold filling pressure of $30 \mathrm{Mpa}$ was adopted when filling, the casting speed was $38 \mathrm{~mm} / \mathrm{s}$, and air cooling was the preferred method of cooling.

\section{Numerical simulation analysis}

During the filling process, the air entrainment will be produced due to the turbulent flow in the flow process, and the defects such as shrinkage porosity and shrinkage cavity will often occur due to the insufficient filling in the solidification process. $^{[11,12]}$ Therefore, it is very important to accurately reproduce the casting filling solidification process to predict the defects such as air entrainment, slag inclusion, shrinkage porosity and shrinkage cavity. ${ }^{[13,14]}$ In the filling process, the quality of casting system design and possible defects can be preliminarily determined by the intensity of the change of flow velocity and direction. In the solidification process, if the liquid phase isolated region is generated in the casting, the location of liquid phase isolated region and possible defects can be preliminarily determined. The location and size of the defects can be predicted after solidification. ${ }^{[15-18]}$

The analysis of the temperature field of liquid metal filling and solidification can predict the location of defects and provide guidance for process improvement. ${ }^{[19]}$ The time for the metal liquid to enter the mold cavity through the gating system is $2.1427 \mathrm{~s}$. At this point the metal liquid flow speed is faster, there is a possibility of air entrapment. The metal liquid flows through the inner gate and fills to both sides respectively. At $4.0177 \mathrm{~s}$, both sides of the metal liquid had been completely converged, continue to fill the cavity upward. The metal fluid flow is relatively stable and the possibility of air entrainment is reduced. The final filling time is $7.5303 \mathrm{~s}$ as shown in Fig.3.

Table 1 Numerical simulation of Process parameters.

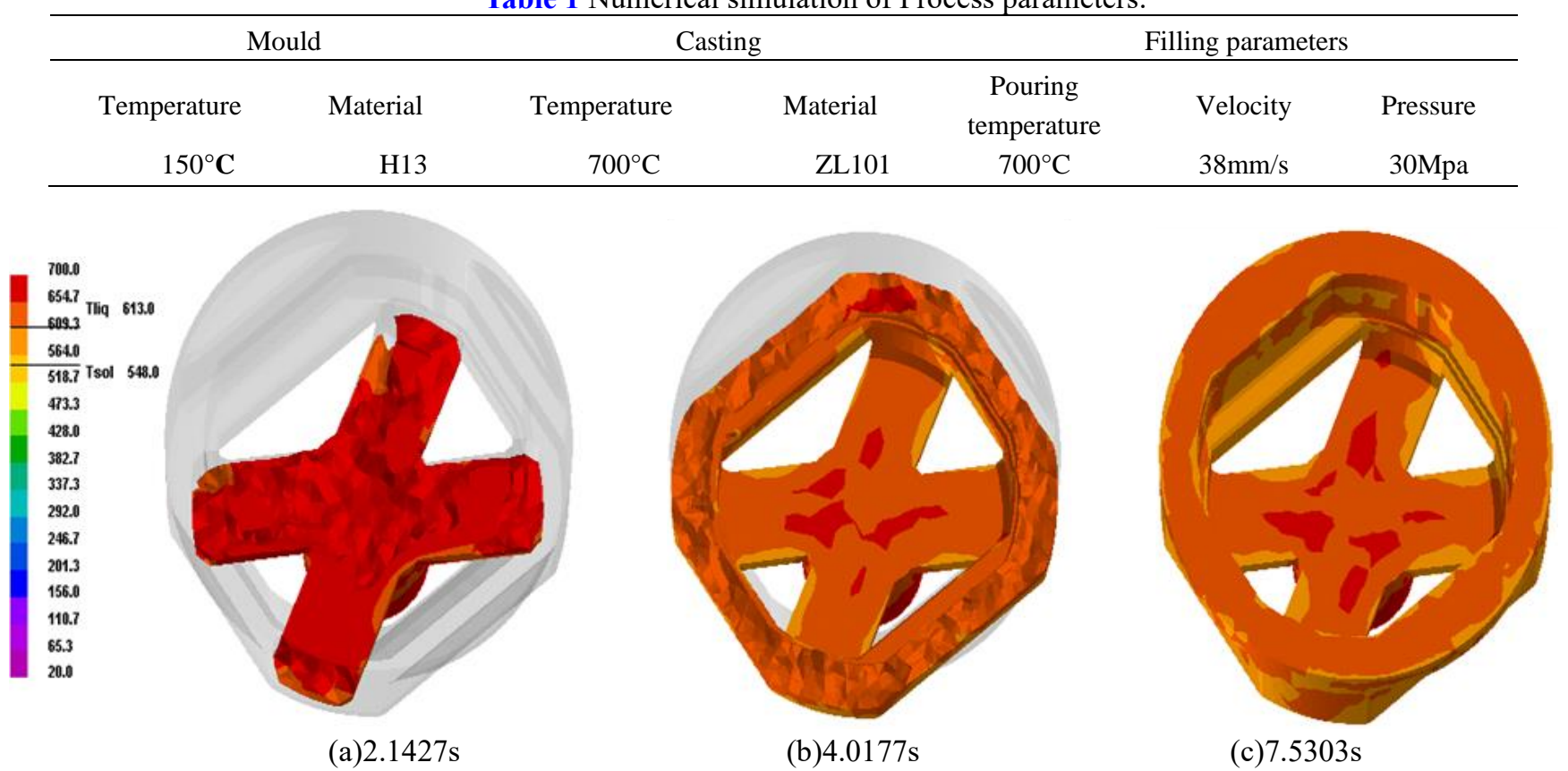

Fig. 3 The temperature field distribution of the adapter ring during the filling process $\left({ }^{\circ} \mathrm{C}\right)$. 


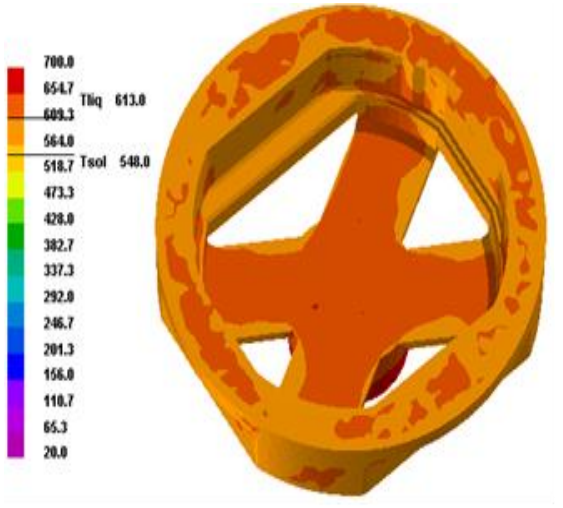

(a) $7.8153 \mathrm{~s}$

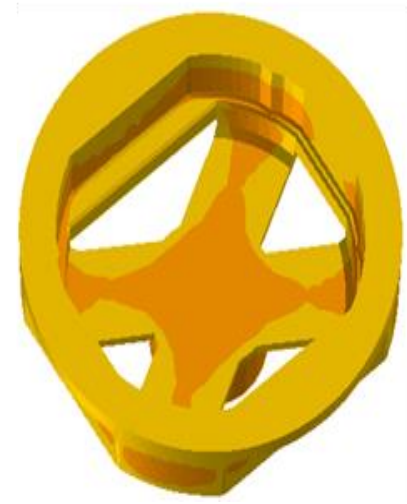

(b) $27.3353 \mathrm{~s}$

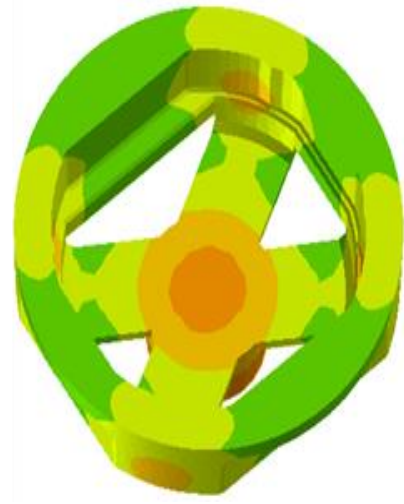

(c) $44.8353 \mathrm{~s}$

Fig. 4 The temperature field distribution of the adapter ring during the solidification process $\left({ }^{\circ} \mathrm{C}\right)$.

During the solidification process of the metal liquid, due to the chilling effect of the mold, the larger the temperature gradient, the faster the dendrites grow along the heat flow side. ${ }^{[20-22]}$ The metal liquid in contact with the mold first starts to solidify, as shown in Fig. 4(a). As the solidification progresses, due to the small cross-sectional area of the runner, the runner starts to solidify. But at this time, a large part of the casting has not solidified, as shown in Fig. 4(b). The final runner is completely solidified with an isolated molten pool at the casting wall thickness, as shown in Fig. 4(c).
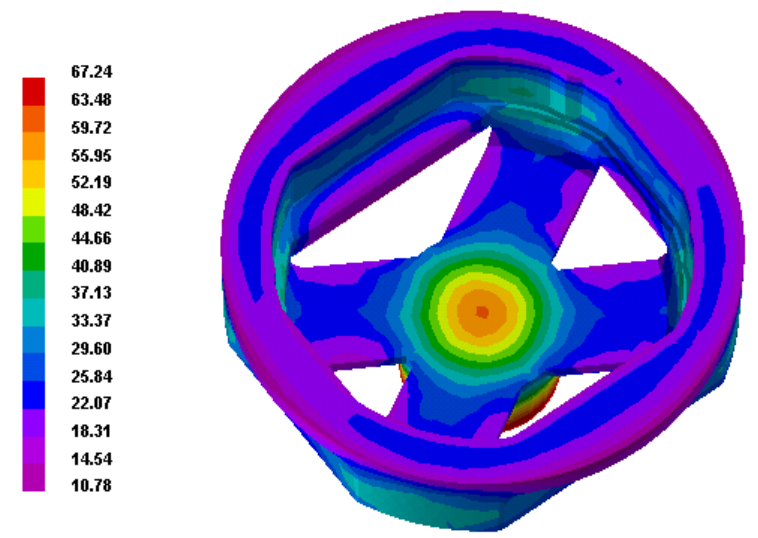

Fig. 5 Solidification time of casting parts(s).

Squeeze casting is the solidification of liquid metal under pressure. The pressure needs to pass through the runner to the casting, and the casting is retracted through the runner to eliminate defects in the casting. ${ }^{[23,24]}$ The solidification time of each part of casting was analyzed as shown in Fig. 5. The solidification time of the runner is $24 \mathrm{~s}$, while the solidification time of the four corner wall thickness parts of the casting is $41 \mathrm{~s}$. Since the runner solidifies before the casting for $17 \mathrm{~s}$, when the punch exerts pressure on the straight runner, it has no effect on the casting. Then the temperature field of casting solidification at $80 \%$ was analyzed, as shown in Fig. 6 . The runner has solidified when $80 \%$ of the casting has solidified. However, most of the castings are still in solid-liquid coexistence, and the pressure exerted on the straight runner cannot be transferred to the casting, so the casting is likely to cause shrinkage cavity and porosity in this part. Fig. 7 shows the picture of the casting wall thickness cut after the squeeze casting with this scheme. From this figure, it can be clearly seen that the casting has shrinkage cavity defect in this part, which conforms to the simulation prediction results.

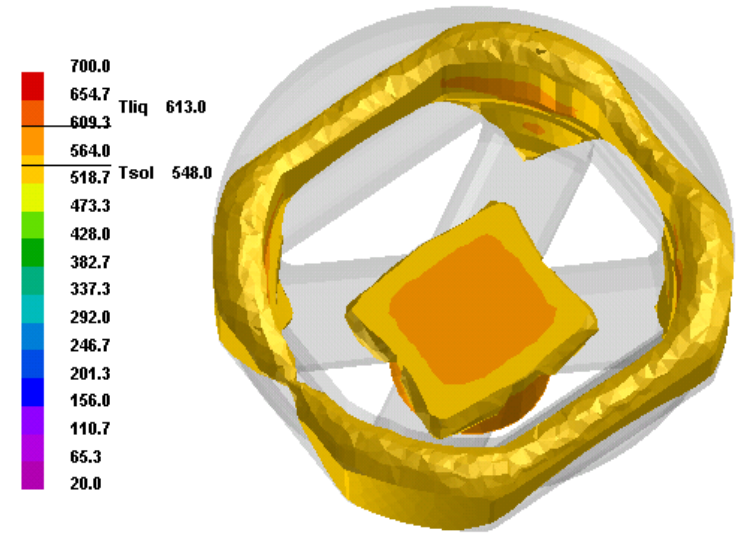

Fig. 6 The solid-liquid coexistence distribution of casting solidification at $80 \%\left({ }^{\circ} \mathrm{C}\right)$.

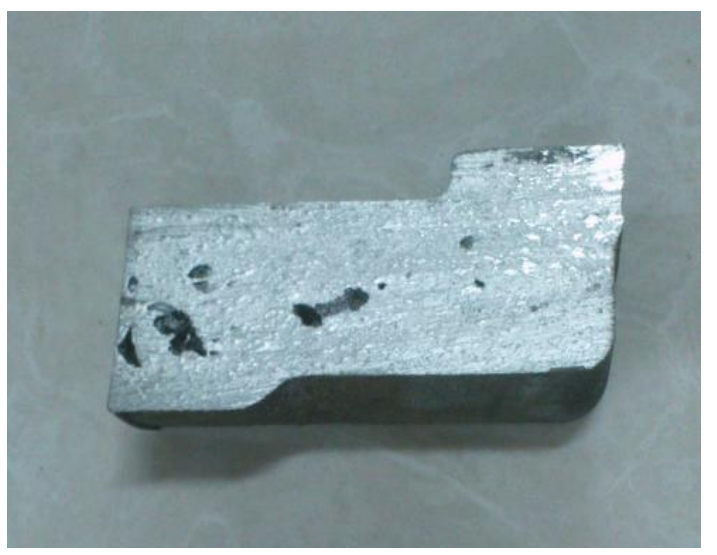

Fig. 7 A section of thick wall.

\section{Improvement of indirect squeeze casting process for adapter ring casting}

According to the analysis results of the initial process scheme, the actual indirect squeeze casting with this scheme is likely to cause shrinkage cavity and porosity defects in the four 


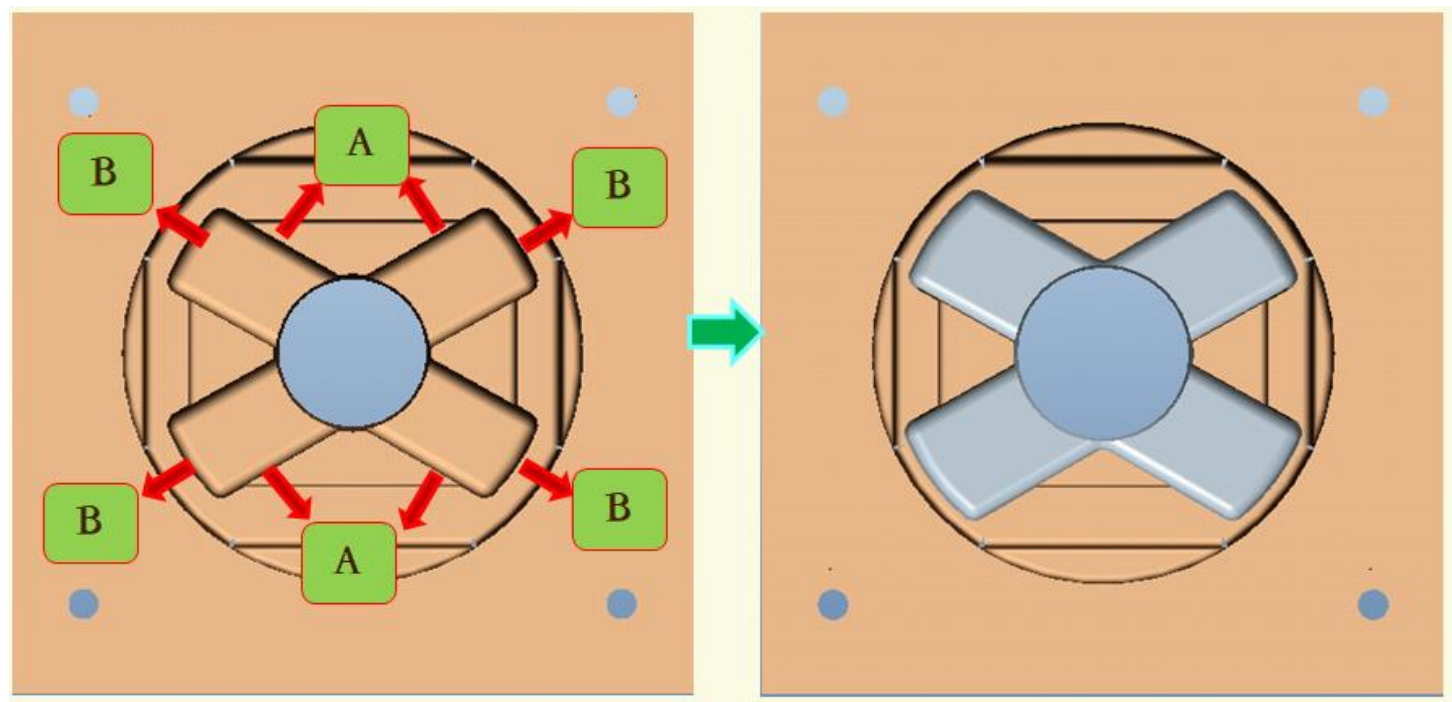

Fig. 8 Mold modification scheme.

corner wall thickness parts of the casting. In order to ensure the high quality of the castings in the actual production, the process improvement is carried out on the basis of this scheme, which is mainly to widen the cross section of the runner and increase the cross-sectional area of the inner gate. As shown in Fig. 8, the width of the runner in the direction A and B should be increased by $10 \mathrm{~mm}$ and $5 \mathrm{~mm}$ respectively. Meanwhile, the diameter of the straight runner should be expanded from $\phi 80 \mathrm{~mm}$ to $\phi 90 \mathrm{~mm}$.

The filling and solidification of the modified castings were simulated. As can be seen from Fig. 9, the solidification time of the casting increases, and the difference between the solidification time of the runner and that of the four corners of the casting decreases. As shown in Fig. 10, when the casting solidifies $80 \%$ and $85 \%$, there was an unsolidified metal molten pool at the wall thickness of the casting. However, there are still many parts of the runner that have not yet solidified. At this time, the punch of the extruder exerts pressure on the runner. The pressure can be transferred to the casting through the runner, under the action of applied stress, the grain boundary migrates. The structures and arrangements of grain boundary dislocations at different misorientation angles are very different. ${ }^{[25,26]}$ and the ability to fill shrinkage is enhanced, which can greatly reduce the shrinkage cavity and porosity and other defects.

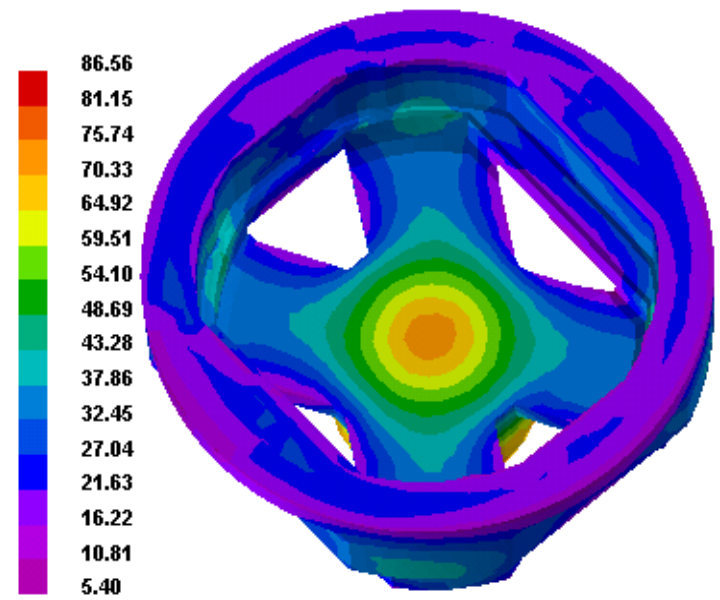

Fig. 9 Solidification time of each part of casting after process improvement.

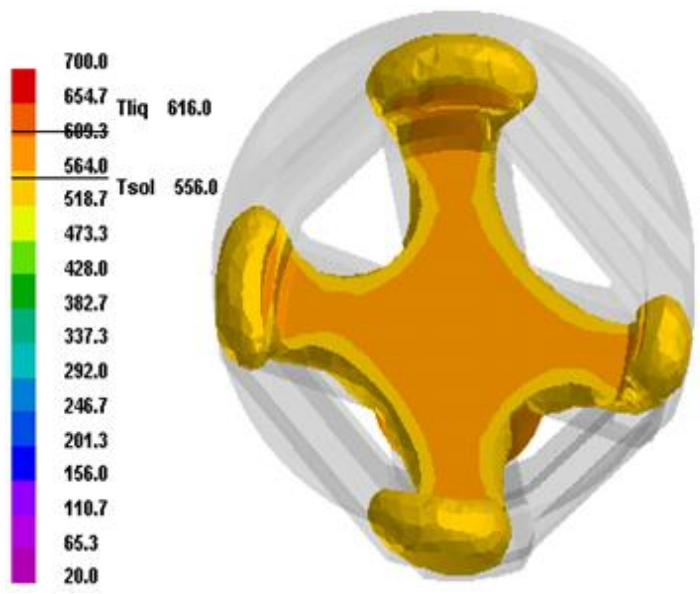

(a) $80 \%$ of solidification

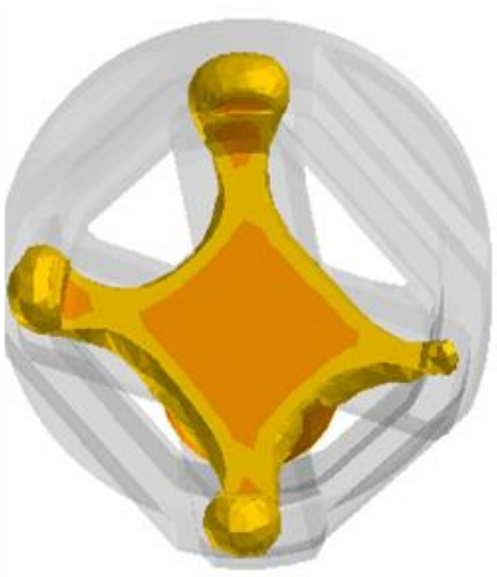

(b) $85 \%$ of solidification

Fig. 10 The coexistence distribution of solid and liquid state during casting solidification after process improvement. 


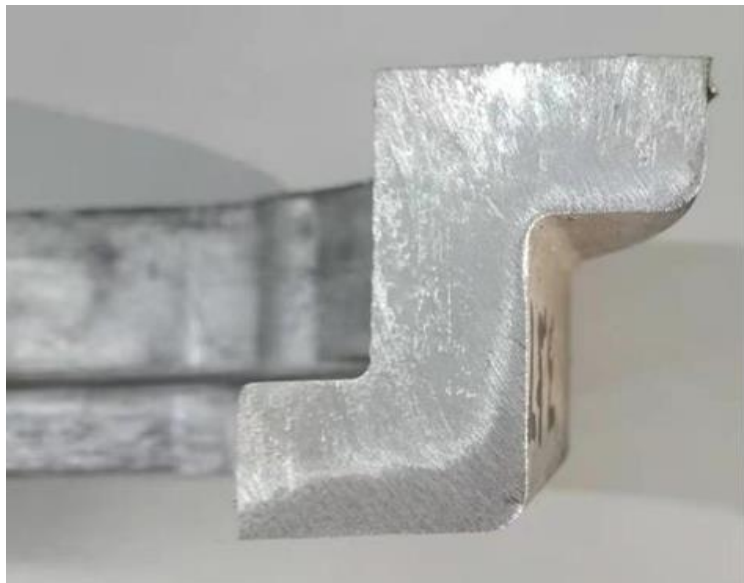

(a) A section of thick wall

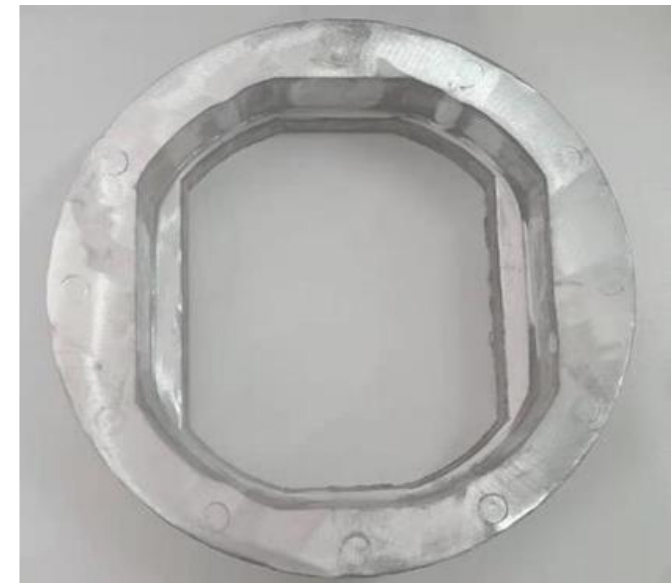

(b) Removing the sprue

Fig. 11 Adapter ring after indirect squeeze casting.

Fig. 11(a) showed a section of the adapter ring casting' thick wall after indirect squeeze casting, Fig. 11(b) showed the adapter ring casting after the runner was removed, and no shrinkage cavity, porosity and other defects were found in the thickness section of the casting. It can be seen that the process scheme can guarantee the casting quality and obtain the castings without shrinkage cavity and porosity defect, which indicates that more accurate results can be obtained by simulating the squeeze casting process and improving it, which has guiding significance to the actual production.

\section{Conclusion}

As an advanced forming technology, indirect extrusion casting can effectively improve the mechanical properties of the casting and reduce the shrinkage cavity and porosity of the casting compared with the die casting process. Meanwhile, the casting can be further improved by heat treatment. However, indirect squeeze casting also has its limitations. Because punch is only partially pressurized on the casting, the pressurization effect is poor and it is difficult to improve the densification of the casting structure. Moreover, after the metal liquid is injected into the mold cavity through the gating system, the temperature of the metal liquid has decreased and solidified after it reaches the mold cavity, and the runner part has also started to solidify. The transfer pressure effect is not good, so the casting will have shrinkage cavity and porosity and other defects. Therefore, in the design of indirect extrusion casting mold, full consideration should be given to the feeding effect of runner. By using the simulation software to simulate the temperature field of casting filling and solidification, and observing the simulation results, the reasonable process scheme can be improved based on the basis, and a more suitable process can be obtained, so as to shorten the trial production period and improve the research and development efficiency.

\section{Acknowledgments}

This work was supported by the National Natural Science Foundation of China (Nos. 52074246, 22008224, 51774253,
51774254); Science and Technology Major Project of Shanxi Province (Nos. 20191102008, 20191102007); Platform and Talent Project of Shanxi Province (No. 201805D211036); Guiding Local Science and Technology Development Projects by the Central Government (No. YDZX20191400002796).

\section{Supporting Information}

Not applicable

\section{Conflict of interest}

There are no conflicts to declare.

\section{References}

[1] W. Rong, L. E. Qichi, W. Engang, C. Jianzhong, R. Zheng, C. Xiangyu, Z. Xiao, Z. Xiurong and C. Min, J. Aeronau. Mater, 2018, 38, 75-81, doi: 10.11868/j.issn.1005-5053.2017.000156.

[2] M. R. Ghomashchi, A. Vikhrov J. Mater. Process. Tech., 2000, 101, 1-9, doi: 10.1016/S0924-0136(99)00291-5.

[3] Chen Liwen; Hou Hua; Jin Yuchun; Zhao Yuhong; Kang Yongsheng, Rare Metal Mat. Eng., 2018, 47, 1174-1179.

[4] L. Chen, Y. Zhao, Z. Wen, J. Tian, H. Hou. Mater. Res-IberoAm. J., 2017, 20, 1274-1281, doi: 10.1590/1980-5373-mr-20170300 .

[5] K. Sukumaran, K. K. Ravikumar, S.G.K. Pillai, T. P. D. Rajan, M. Ravi, R.M. Pillai, B. C. Pai, Mater. Sci. Eng. A, 2008, doi: 10.1016/j.msea.2008.01.054.

[6] Z. Ming, Z. Wei-Wen, Z. Hai-Dong, Z. Da-tong L. Yuan-yuan, T. Nonferr. Metal. Soc., 2007, 17, 496-501, doi: 10.1016/S10036326(07)60122-8.

[7] T. F. Li, D. S. Sui, Z. S. Cui, Foundry, 2006. doi: 10.1016/S0379-4172(06)60085-1.

[8] Q. M. Chang, C. J. Chen, S. C. Zhang, D. Schwam, Inter. J. Cast Metal Resea., 2013, 23, 30-36, doi: 10.1179/174313309X449309.

[9] Y. Wang, J. Liu, Q. Chen, D. Cao, Spec. Cas. \& Nonferr. Alloy, 2011, 31, 1024-1027, doi: 10.3870/tzzz.2011.11.012. 
[10] G. Wang, Spec. Cas. \& Nonferr. Alloy, 2013, 33, 17-20.

[11] H. Hou, H. H. Ge Y. H. Zhao and Y. M. Yang, Adv. Mater. Resea., 2013, 641-642, 309-314, doi: 10.1007/s00170-016-88454.

[12] M. J. Couper, A. E. Neeson, J. R. Griffiths, Fat. Fract. Eng. Mater. Struct., 2010, 13, 213-227, doi: 10.1111/j.14602695.1990.tb00594.x.

[13] Q.Wang, G. P. Backer, D. L. Metzger, Method for simulating casting defects and microstructures of castings: US 2013.

[14] J. Zhang, H. Wang, W. Kuang, Y. Zhang, S. Li, Y. Zhao, D. M. Herlach Acta Mater., 2018, 148, 86-99, doi; 10.1016/j.actamat.2018.01.040.

[15] S. Y. Kwak, J. K. Choi, Foundry, 2011, 60, 414-418.

[16] G. Hongxing, Y. Zhiqiang, Foundry Technology, 2016.

[17] R. Q. Yao, H. Q. Tang, Adv. Mater. Res., 2011, 299-300, $955-$ 961, doi; 10.4028/www.scientific.net/AMR.299-300.955.

[18] W. Kuang, H. Wang, X. Li, J. Zhang, Q. Zhou, Y. Zhao Acta Mater., 2018, 159, 16-30, doi: 10.1016/j.actamat.2018.08.008.

[19] L. Chen, Y. Zhao, F. Yan, H. Hou, J. Alloy Comp., 2017, 725, 673-683, doi: 10.1016/j.jallcom.2017.07.169.

[20] Y. Zhao, B. Zhang, H. Hou, W. Chen, M. Wang, J. Mater. Sci. Techn., 2019, 35, 1044-1052, doi: 10.1016/j.jmst.2018.12.009.

[21] H. Guo, Y. Zhao, Y. Sun, J. Tian, H. Hou, K. Qi, X. Tian, Superlattice. Microst., 2019, 129, 163-175, doi: 10.1016/j.spmi.2019.03.020.

[22] L. Chen, Y. Zhao, H. Hou, T. Zhang, J. Liang, M. Li, J. Li, J. Alloy Compd., 2019, 778, 359-374, doi: 10.1016/j.jallcom.2018.11.148.

[23] R. Li, R. D. Li, Y. H. Bai, T. Nonferr. Metal. Soc., 2010, 20, 59-63, doi: 10.1016/S1003-6326(09)60097-2.

[24] R. D. Li, H. S. Yu, C. X. Li, Foundry, 2006, 36, 377-386. doi:10.1006/jers.2002.0473.

[25] B. Zhang, Y. Zhao, W. Chen, Q. Xu, M. Wang, H. Hou, S. Wang, J. Crys. Grow., 2019, 522, 183-190, doi: 10.1016/j.jcrysgro.2019.06.027

[26] K. Qi, Y. Zhao, X. Tian, D. Peng, Y. Sun, H. Hua. Acta Phys. Sin., 2019, 68, 170504, doi: 10.7498/aps.68.20190051.

\section{Author information}

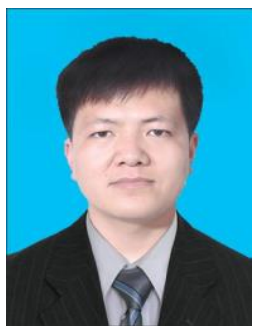

\section{Liwen Chen}

Institution: College of Materials Science and Engineering, North University of China, Taiyuan, 030051, China

Title: Lecturer

Email: chenliwen@nuc.edu.cn

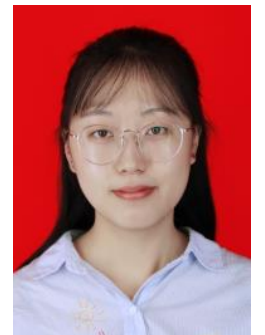

\section{Jingyi Li}

Institution: College of Materials Science and Engineering, North University of China, Taiyuan, 030051, China

Title: Master student

Email: lijingyi753@163.com

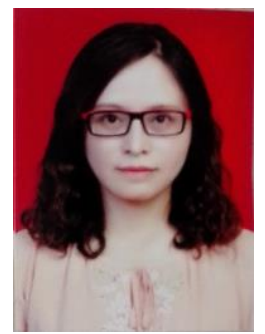

\section{Yuhong Zhao}

Institution: College of Materials Science and Engineering, North University of China, Taiyuan, 030051, China

Title: Professor

Email: zhaoyuhong@nuc.edu.cn

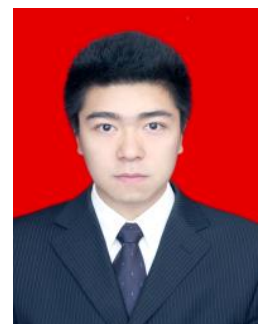

\section{Muxi Li}

Institution: College of Materials Science and Engineering, North University of China, Taiyuan, 030051, China

Title: Doctor student

Email:819910908@qq.com

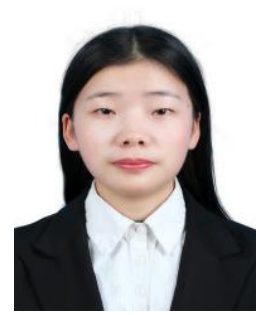

\section{Limin Li}

Institution: College of Materials Science and Engineering, North University of China, Taiyuan, 030051, China

Title: Doctor student

Email:1723212558@qq.com

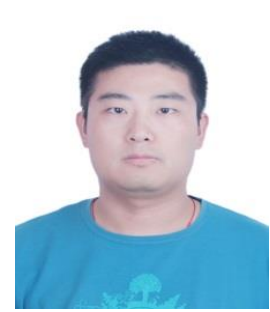

\section{Lei Chen}

Institution: Fenxi Shanxi Heavy Industry Co., Ltd.

Title: senior engineer

Email:cl19862008@163.com

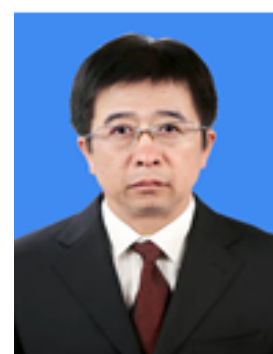

\section{Hua Hou}

Institution: College of Materials Science and Engineering, North University of China, Taiyuan, 030051, China

Title: Professor

Email:houhua@nuc.edu.cn

Publisher's Note Engineered Science Publisher remains neutral with regard to jurisdictional claims in published maps and institutional affiliations. 